OPEN ACCESS

Edited by:

Yu Ding,

University of Maryland, United States

Reviewed by:

Xiao-Dong Zhu,

Qingdao University of Science and

Technology, China

*Correspondence:

Wei Guo

weiguo7@bit.edu.cn

Yumin Qian

yuminqian@bit.edu.cn

Specialty section: This article was submitted to

Electrochemistry,

a section of the journal

Frontiers in Chemistry

Received: 10 December 2021

Accepted: 10 January 2022

Published: 14 February 2022

Citation:

Li R, Guo W and Qian Y (2022) Recent Developments of Cathode Materials for Thermal Batteries.

Front. Chem. 10:832972

doi: 10.3389/fchem.2022.832972

\section{Recent Developments of Cathode Materials for Thermal Batteries}

\author{
Renyi Li, Wei Guo* and Yumin Qian* \\ Key Lab of Advanced Optoelectronic Quantum Architecture and Measurement (MOE), School of Physics, Beijing Institute of \\ Technology, Beijing, China
}

Big progress has been made in batteries based on an intercalation mechanism in the last 20 years, but limited capacity in batteries hinders their further increase in energy density. The demand for more energy intensity makes research communities turn to conversiontype batteries. Thermal batteries are a special kind of conversion-type battery, which are thermally activated primary batteries composed mainly of cathode, anode, separator (electrolyte), and heating mass. Such kinds of battery employ an internal pyrotechnic source to make the battery stack reach its operating temperature. Thermal batteries have a long history of research and usage in military fields because of their high specific capacity, high specific energy, high thermal stability, long shelf life, and fast activation. These experiences and knowledge are of vital importance for the development of conversiontype batteries. This review provides a comprehensive account of recent studies on cathode materials. The paper covers the preparation, characterization of various cathode materials, and the performance test of thermal batteries. These advances have significant implications for the development of high-performance, low-cost, and mass production conversion-type batteries in the near future.

Keywords: thermal batteries, cathode materials, metal chlorides, metal fluorides, metal sulfides

\section{INTRODUCTION}

Thermal batteries are a special kind of primary batteries that can be stored in an inactive state for a long time and then activated generally at $350-550^{\circ} \mathrm{C}$ when energy is required (Guidotti and Masset, 2006; Choi et al., 2015). It was first invented and developed in the 1940s to power German weapons (Guidotti and Masset, 2006). The activation time and power density greatly affect the response speed of thermal batteries. Reserved thermal batteries with large capacity, high power, high thermal stability, long shelf lives, and fast activation are an attractive high-temperature battery system, which can be used as an effective power source for the actuator of guided weapons and the propulsion device of underwater and space vehicles (Cho et al., 2020).

From the development history, thermal battery can be divided into three stages as shown in Figure 1. The first-generation calcium/chromate thermal battery had a low energy density, complex reaction mechanism, dendrite formation, and unpredictable performance, which is replaced by the second-generation lithium/sulfides batteries. Currently, the $\mathrm{Li} / \mathrm{FeS}_{2}$ thermal battery with better power and discharging time compared with calcium/chromate counterpart, is widely used in various military weapons and environment. However, with the evolution of military action into an intelligence era and the thriving of space exploration, there are new challenges faced by batteries: energy/power density, discharging time, and activation time. Thus, the $\mathrm{Li} / \mathrm{FeS}_{2}$ battery cannot meet the requirement and new battery technologies are essential to fulfill these needs. In terms of anodes, $\mathrm{Ca}, \mathrm{Mg}$, and $\mathrm{Li}$ or corresponding alloys all have been used as anode materials 


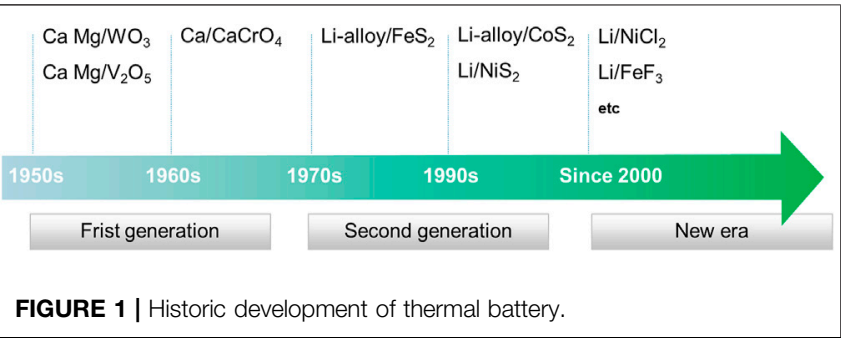

(Guidotti and Masset, 2008). However, only Li or Li-alloy is used at present, so this review only focuses on cathode materials related to Li chemistry. Higher voltage is more practical for a battery with a high-power output. Furthermore, obtaining the same voltage requires fewer single cells with high-voltage, which is beneficial to improve the overall energy density of the battery. Due to the stronger electronegativity of halide elements, halide compounds usually show higher voltages. Thus, metal halide materials are ideal replacement of metal sulfides as cathode materials for thermal batteries. This review highlights the reported metal sulfides and halides, and finally gives a generalization for the future research direction for cathode of thermal batteries.

\section{TRANSITION METAL SULFIDES}

\section{$\mathrm{FeS}_{2}$}

Pyrite is a relatively abundant and cheap natural mineral used as cathode material for thermal batteries (Guidotti et al., 2002). $\mathrm{FeS}_{2}$ has a capacity of $893 \mathrm{mAh} / \mathrm{g}$ with an open circuit voltage (OCV) of $2.0 \mathrm{~V}$ (Ko et al., 2019). It is a typical semiconductor with a bandgap of $0.95 \mathrm{eV}$ (Ennaoui et al., 1993) and begins to decompose at $550^{\circ} \mathrm{C}$. The synthesis of high-purity pyrite powder from natural mineral for thermal battery requires a complex ground, sizing, and purification process with high cost. The detailed preparation, characterization, and performance tests of $\mathrm{FeS}_{2}$ cathode are shown in Supplementary Figures S1-S5.

Guidotti used the plasma spraying (PS) method (Guidotti et al., 2006) to synthesize $\mathrm{FeS}_{2}$ with $\mathrm{LiCl}-\mathrm{KCl}$ eutectic electrolyte to make the composite cathode, which showed low impedance and was almost 3.5 times (Guidotti et al., 2006) that of the discrete pressed-powder. The performance of batteries with PS cathode had a linear relationship with the number of cells, and the reduced battery components facilitate the battery design by reduced chance of assembly errors. Wang et al. synthesized pyrite films to solve mechanical integrity issues of thin pellets, and the prepared pyrite thin films with several superior physical properties than that of micron pyrite pellets $(\mathrm{Au}, 2003$; Wang et al., 2013). Ko prepared thin-film cathodes with good homogeneity and a reproducible thickness via a tape-casting process (Ko et al., 2017), which can produce a thin sheet with a thickness of 0.01 to $1.2 \mathrm{~mm}$, as well as the possibility of controlling density, surface condition, and the flexibility of synthesis sheets (Park et al., 2016). Such method can be easily scaled up, but increases the internal resistance of the battery due to the presence of different polymer binders (Masset et al., 2005; Cha et al., 2018). Various studies shows the phase transformations of $\mathrm{FeS}_{2}$ discharging process as follows (Tomczuk et al., 1982; Choi et al., 2014; Chen et al., 2017; Cha et al., 2018; Zhang and Tran, 2018; Kim et al., 2020; Zou et al., 2020; Thu et al., 2021): $\mathrm{FeS}_{2} \rightarrow \mathrm{Li}_{3} \mathrm{Fe}_{2} \mathrm{~S}_{4} \rightarrow \mathrm{Li}_{2+\mathrm{x}} \mathrm{Fe}_{1-\mathrm{x}} \mathrm{S}_{2} \rightarrow \mathrm{Fe}$.

\section{$\mathrm{CoS}_{2}$}

In special high-power and long discharging time applications, $\mathrm{FeS}_{2}$ is replaced by $\mathrm{CoS}_{2}$ due to its excellent thermal stability $\left(650^{\circ} \mathrm{C}\right)$, metal-like electrical conductivity, and discharge performance (Preto et al., 1983; Guidotti et al., 2002; Guidotti and Masset, 2006). The capacity of $\operatorname{CoS}_{2}$ is $871 \mathrm{mAh} / \mathrm{g}$, and OCV is $1.99 \mathrm{~V}^{23}$. The detailed preparation, characterization, and performance tests of $\mathrm{CoS}_{2}$ cathode are shown in Supplementary Figures S6-S8.

Guidotti prepared $\mathrm{CoS}_{2}$ cathode via an aqueous process (Guidotti et al., 2002) with improved thermal stability after heat treatment at $550^{\circ} \mathrm{C}$. The performance can be enhanced by increasing the $\mathrm{CoS}_{2}$ particle size. Guidotti also showed that thermal spraying catholyte mixtures have distinct advantages for fabrication of thin electrodes for short-life thermal batteries (Guidotti et al., 2006). Xie prepared $\mathrm{CoS}_{2}$ and carbon nanotubes (CNTs) composite cathode using hydrothermal growth method (Xie et al., 2016). The pulse discharge performance of the $\mathrm{CoS}_{2} / \mathrm{CNTs}$ cathode was superior to that of conventional $\mathrm{CoS}_{2}$ due to the enhanced conductivity. Hu used the screening-printing method to prepare a film cathode ( $\mathrm{Hu}$ et al., 2018) with a thickness of $50 \mu \mathrm{m}$ that showed twice the capacity and active material utilization ratio. Xie prepared a novel carbon-coated $\mathrm{CoS}_{2}\left(\mathrm{C} @ \mathrm{CoS}_{2}\right)$ cathode material via a facile onepot hydrothermal method (Xie et al., 2017) to prevent the $\operatorname{CoS}_{2}$ oxidation when exposing to air (Masset and Guidotti, 2008a; Masset and Guidotti, 2008b). The decomposition temperature of $\mathrm{C} @ \mathrm{CoS}_{2}$ was $610^{\circ} \mathrm{C}$, which was $200^{\circ} \mathrm{C}$ higher than that of $\operatorname{CoS}_{2}$ nanocrystal (Masset and Guidotti, 2008a). Xie used carboncoated $\mathrm{CoS}_{2}$ as the cathode to inhibit the higher self-discharge rate in the $\mathrm{Li}-\mathrm{B} / \mathrm{CoS}_{2}$ system (Xie et al., 2018).

There are many phases in the Co-S phase diagram, such as $\mathrm{CoS}_{2}$ (space group $\mathrm{Pa}-3$ ), $\mathrm{Co}_{3} \mathrm{~S}_{4}$ (space group $\mathrm{Fd}-3 \mathrm{~m}$ ), $\mathrm{Co}_{9} \mathrm{~S}_{8}(\mathrm{Fm}$ $3 m)$, and $\operatorname{CoS}\left(\mathrm{PG}_{3} / \mathrm{mmc}\right)$ (Masset and Guidotti, 2008b). Although the electrochemical performances of $\mathrm{CoS}_{2}$-based thermal batteries have been studied for many years, little is known about the phase evolution of $\mathrm{CoS}_{2}$ in the discharge process of thermal batteries. Previous studies showed that the phase transformation during the discharge process of $\mathrm{CoS}_{2}$ followed the $\mathrm{CoS}_{2} \rightarrow \mathrm{Co}_{3} \mathrm{~S}_{4} \rightarrow \mathrm{Co}_{9} \mathrm{~S}_{8} \rightarrow$ Co pathway (Masset, 2008). Payne's powder neutron diffraction study showed that the phase transformations of the $\mathrm{CoS}_{2}$ discharging process followed the $\mathrm{CoS}_{2}-\mathrm{CoS}-\mathrm{Co}_{9} \mathrm{~S}_{8}$-Co pathway (Payne et al., 2019).

\section{$\mathrm{NiS}_{2}$}

The low-cost $\mathrm{NiS}_{2}$ was regarded as one of the promising cathode material candidates because the thermal stability and discharge performance of $\mathrm{NiS}_{2}$ were between $\mathrm{FeS}_{2}$ and $\mathrm{CoS}_{2}{ }^{27}$. However, $\mathrm{NiS}_{2}$ cathode cannot fully react at high current density, which becomes a key problem for thermal batteries (Jin et al., 2018). 
Nanocrystallization is an effective method to improve the specific capacity of cathode (Xu et al., 2014; Yu et al., 2016; Liu et al., 2017a; Yu et al., 2017). Moreover, the intermediate phase evolution and reaction speed could benefit from the merit of nanostructured cathode materials (Sen and Mitra, 2013). The more discharge steps appeared in the discharge curve, the more complete the $\mathrm{NiS}_{2}$ cathode reaction. Jin prepared nanostructured $\mathrm{NiS}_{2}$ using nickel carbonyl and sulfur powder as precursors by ball milling, which resulted in a double increase in specific capacity (Jin et al., 2017a).

Although nanocrystallizaiton can be used to improve the intermediate reaction rate and utilization rate of $\mathrm{NiS}_{2}$, it decreases the decomposition temperature (Ji et al., 2014; Yang et al., 2014; Xie et al., 2016), which makes it suitable only for thermal batteries with short life time (discharge temperature $\leq 500^{\circ} \mathrm{C}$ ). Jin employed hierarchical carbon modification to enhance the thermal stability and conductivity of nanostructured $\mathrm{NiS}_{2}$ with significantly higher discharge performance than the pristine $\mathrm{NiS}_{2}$ with much higher resistance (Jin et al., 2018). Hierarchical carbon modification not only increased the initial decomposition temperature but also prevented the further decomposition of residual $\mathrm{NiS}_{2}$. The characterization and performance tests of the nanostructured $\mathrm{NiS}_{2}$ powder are shown in detail in Supplementary Figure S9.

The Ni-S phase diagram exhibits various $\mathrm{Ni}_{\mathrm{X}} \mathrm{S}_{\mathrm{Y}}(\mathrm{X} \leq 7, \mathrm{Y} \leq 6)$ polymorphism structures (Payne et al., 2017). However, despite years of studies, little is known about how the crystalline phases in batteries evolve at high temperatures (Payne et al., 2017).

The HRTEM measurement confirms that the phase transformations of the $\mathrm{NiS}_{2}$ discharging process followed the $\mathrm{NiS}_{2} \rightarrow \mathrm{NiS} \rightarrow \mathrm{Ni}_{7} \mathrm{~S}_{6} \rightarrow \mathrm{Ni}_{3} \mathrm{~S}_{2} \rightarrow \mathrm{Ni}$ pathway (Jin et al., 2017a). Payne's in situ powder neutron diffraction study (Payne et al., 2017) showed that the phase transformations of $\mathrm{NiS}_{2}$ the discharging process followed the $\mathrm{NiS}_{2} \rightarrow \mathrm{NiS} \rightarrow \mathrm{Ni}_{2} \mathrm{~S}_{3} \rightarrow \mathrm{Ni}$ pathway.

In recent years, transition metal dichalcogenides (TMDs) have received considerable attention due to their novel layer structure (Zhang et al., 2018) with unique properties, which endow great potential in catalysis (Liang et al., 2020; Sarma et al., 2020; Xu et al., 2020; Zeng et al., 2020; Wang et al., 2021), energy storage, and conversion (Gao et al., 2016; Li et al., 2019). Various TMDs have been reported as thermal battery cathode material with high decomposition temperature and capacity, such as $\mathrm{MoS}_{2}$ (Zheng et al., 2018), $\mathrm{WS}_{2}$ (Guo et al., 2019a), NiMoSs (Yusong Choi, 2019), and $\mathrm{ZrS}_{3}$ (Giagloglou et al., 2016). These materials show various advantage over traditional $\mathrm{FeS}_{2}$, which deserve detailed study in the future.

\section{TRANSITION METAL CHLORIDE}

It is urgent to develop new cathode materials for thermal batteries with high power and energy output capability, miniaturization, and micromation to adapt to the rapid development of weapon and space exploration system (Tian et al., 2021), which is difficult for these traditional cathode materials (Liu et al., 2017b). The detailed synthesis, characterization, and performance tests of $\mathrm{NiCl}_{2}$ are exhibited in Supplementary Figures S10-S12.

$\mathrm{NiCl}_{2}$ is considered an ideal substitute cathode material for $\mathrm{FeS}_{2}$ and matches the excellent performance of Li alloy anode due to its relative high potential $(2.5-3 \mathrm{~V}$ vs $\mathrm{Li})$, high discharge current, high specific energy, and low cost (Guidotti et al., 2006; Ying et al., 2016; Liu et al., 2017b). However, the high solubility of $\mathrm{NiCl}_{2}$ in molten salt electrolyte can cause short circuit. Due to the low conductivity and poor electrochemical activity of $\mathrm{NiCl}_{2}$, the activation time is longer, so a certain amount of conductive additives must be added to improve its conductivity (Jai Prakash, 2000; Jin et al., 2017b; Gui et al., 2020; Tian et al., 2021).

The thermal stability of $\mathrm{NiCl}_{2}$ was primarily affected by the crystal water and oxide impurities during low-temperature predehydration. Thus, surface and sublimation treatment of hydrate $\mathrm{NiCl}_{2}$ are necessary to modify the microstructure and make large specific surface area to boost the electrochemical performance. Jin prepared pure $\mathrm{NiCl}_{2}$ by vacuum sintering after sublimation and synthesized the carbon-coated $\mathrm{NiCl}_{2}$ via a simple solid-state reaction (Jin et al., 2017b). The carbon-coated $\mathrm{NiCl}_{2}$ cathode showed drastic improvement in capacity, specific energy, and discharging time. The electrochemical mechanism was shown as follows:

$$
2 \mathrm{Li}+\mathrm{NiCl}_{2} \rightarrow 2 \mathrm{LiCl}+\mathrm{Li}
$$

The carbon coating enhanced the electronic conductivity and led to the reduced activation time. At the same time, the carbon coating increased the structure stability and reduced the solubility of $\mathrm{NiCl}_{2}$ by protecting the $\mathrm{NiCl}_{2}$ from directly contacting the electrolyte. However, it also resulted in a greater voltage delay during the initial discharge process. $\mathrm{Hu}$ filled sublimated $\mathrm{NiCl}_{2}$ into $\mathrm{Ni}$ foam instead of compact stainless steel screen printing (Hu et al., 2017). The discharge voltage of the $\mathrm{NiCl}_{2}$-based single cell with $\mathrm{Ni}$ foam substrate was $2.55 \mathrm{~V}$. Compared with $\mathrm{NiCl}_{2}$ cathode with stainless steel substrate, the electrochemical test showed that the $\mathrm{NiCl}_{2} / \mathrm{Ni}$ foam cathode had more than twice the capacity, had almost one-third of the internal resistance, and had a power density of $10.866 \mathrm{~kW} / \mathrm{kg}$, which outweighed the sulfide batteries. $\mathrm{Ni}$ foam substrate can enhance the electronic conductivity, causing the fast electron transfer and reaction (Xie et al., 2017). Liu proposed a novel two-step variable temperature solid-state method to remove the crystal water from $\mathrm{NiCl}_{2}$ hexahydrate (Liu et al., 2017b). The study showed that the sintering temperatures influenced the morphology of materials, which induced the reduction in discharging time and specific capacity. The two-step variable-temperature preparation method was an effective method to enhance the thermal stability of $\mathrm{NiCl}_{2}$ cathode materials. The $600^{\circ} \mathrm{C}$-treated cathode exhibited better specific capacities of 210.42 and $242.84 \mathrm{mAh} / \mathrm{g}$ at 0.5 and 2.0 A. Giagloglou prepared $\mathrm{NiCl}_{2}$ by solid-state reaction in sealed evacuated quartz tubes, which showed enhanced performance (Giagloglou et al., 2018) and whose specific capacity was achieved at $360 \mathrm{mAh} / \mathrm{g}$ under $500^{\circ} \mathrm{C}$. By using a simple hydrogen etching technique, Gui successfully modified the Ni content and surface roughness (Gui et al., 2020). At different etching conditions, the 

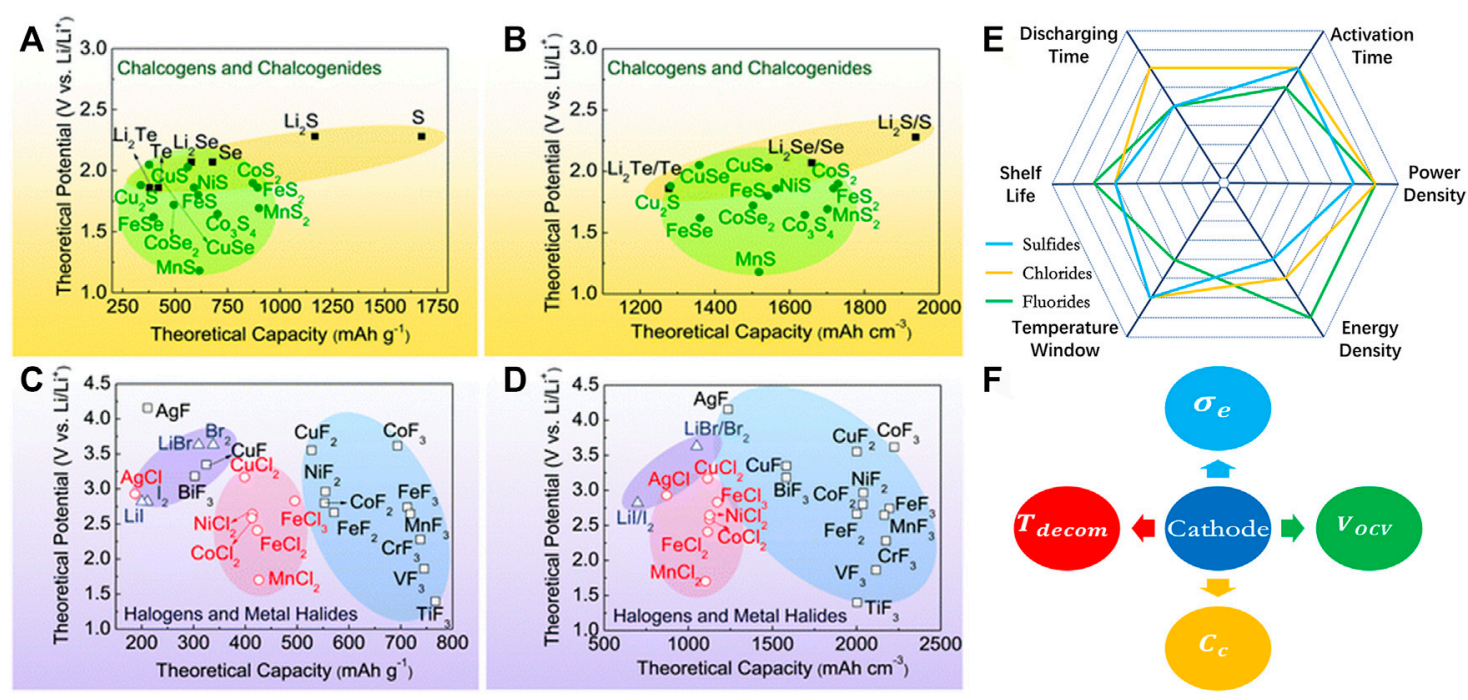

FIGURE 2 | Theoretical gravimetric and volumetric capacities and theoretical potential of selected conversion cathode materials: (A,B) chalcogens and chalcogenides; (C,D) halogens and metal halides (reproduced from Wu and Yushin, 2017, Copyright 2017 Royal Society of Chemistry). (E) Comparison for the various properties of thermal batteries using sulfides, chlorides, and fluorides as the cathode material. (F) The future development directions for the high-performance cathode material of thermal battery.

prepared $\mathrm{NiCl}_{2}$ showed higher discharge voltage and significantly shorter activation time than those of the pure $\mathrm{NiCl}_{2}$ cathode. The discharge voltage and specific power of the prepared $\mathrm{NiCl}_{2}$ via hydrogen etching technique were $2.43 \mathrm{~V}$ and $7.59 \mathrm{~kW} / \mathrm{kg}$. The fabricated the $\mathrm{Ni}-\mathrm{NiCl}_{2}$ composite cathode material via hydrogen reduction by Tian et al. (2021) showed higher voltage and much shorter activation time, and half of the internal resistance and the power density was up to $11.4 \mathrm{~kW} / \mathrm{kg}$.

Additionally, $\mathrm{PbCl}_{2}$ was reported as cathode material (Chen et al., 2021). Although $\mathrm{PbCl}_{2}$ had a relatively low theoretical specific capacity $(193 \mathrm{mAh} / \mathrm{g})$, due to the high utilization rate, it still may increase the energy density of the battery. Giagloglou synthesized $\mathrm{KNiCl}_{3}, \mathrm{Li}_{2} \mathrm{MnCl}_{4}$, and $\mathrm{Li}_{6} \mathrm{VCl}_{8}$ via solid-state reaction and used them in the thermal battery (Giagloglou et al., 2018). Compared with well-known metal disulfide, these transition metal chlorides provided greater specific power and exhibited higher voltage, which can be considered as promising alternative materials for Li thermal battery applications.

\section{TRANSITION METAL FLUORIDES}

Transition metal fluorides (TMFs) have attracted much attention because of their high voltage, specific energy, and excellent thermal stability (Yamakawa et al., 2009; Kim et al., 2010; Chun et al., 2016; Sheng Nan Guo and Wang, 2019; Chang et al., 2020). The ionic bond property of TMFs results in a high working potential (Li et al., 2012). The theoretical potential of the most attractive cathode material, $\mathrm{CuF}_{2}$, is up to $3.55 \mathrm{~V}$ with a specific capacity as high as $528 \mathrm{mAh} / \mathrm{g}$ and a specific energy of $1.87 \mathrm{~kW} \mathrm{~h} / \mathrm{kg}$ (Yamakawa et al., 2009). The theoretical potential of $\mathrm{NiF}_{2}$ is $2.96 \mathrm{~V}$, and the specific capacity is $554 \mathrm{mAh} / \mathrm{g}$. Chang prepared pure $\mathrm{NiF}_{2}$ via a direct and simple two-step dehydration method from commercial $\mathrm{NiF}_{2} \cdot 4 \mathrm{H}_{2} \mathrm{O}$ (Chang et al., 2020). The discharge mechanism was as follows:

$$
\mathrm{NiF}_{2}+2 \mathrm{Li} \rightarrow 2 \mathrm{LiF}+\mathrm{Ni}
$$

Their electrochemical tests of $\mathrm{NiF}_{2}$ cathode showed that there was a voltage platform approximately $2.4 \mathrm{~V}$ at $0.1 \mathrm{~A} / \mathrm{cm}^{2}$ under $520^{\circ} \mathrm{C}$. The maximum voltage plateau can reach $2.5 \mathrm{~V}$ when the temperature is raised up to $580^{\circ} \mathrm{C}$, and the corresponding specific power was $3.7 \mathrm{~kW} / \mathrm{kg}$, making it possible to apply in high specific power thermal batteries. The voltage plateaus dropped in succession when the current density is increased due to the enhanced concentration polarization. The discharge time decreased from 295 to $88 \mathrm{~s}$ when the current density is increased from $0.1 \mathrm{~A} / \mathrm{cm}^{2}$ to $0.5 \mathrm{~A} / \mathrm{cm}^{2}$, which induced a lower specific capacity. The specific power reached up to $16.2 \mathrm{~kW} / \mathrm{kg}$ at a high current density of $0.5 \mathrm{~A} / \mathrm{cm}^{2}$, which proved that $\mathrm{NiF}_{2}$ can be used as the cathode material with high specific power and energy. Compared to the cathode material $\mathrm{NiCl}_{2}$ with long activation time and severe infiltration, the $\mathrm{NiF}_{2}$ exhibited better electrochemical performance. The average resistance was $0.56 \Omega$, which was equivalent to the total polarization. Carbon coating was an effective means to further improve the thermal stability and electrochemical performance of $\mathrm{NiF}_{2}$. The detailed synthesis, characterization, and performance tests of $\mathrm{NiF}_{2}$ are shown in Supplementary Figures S13, S14.

$\mathrm{FeF}_{3}$ is another investigated cathode material (Hua et al., 2021). During the lithiation process, two characteristic discharge voltages of $\mathrm{FeF}_{3}$ were exhibited at about $3 \mathrm{~V}$ and below $2 \mathrm{~V}$, and the corresponding capacities were 237 and 175 $\mathrm{mAh} / \mathrm{g}$, respectively. The electrochemical mechanism of $\mathrm{FeF}_{3}$ follows a three-electron-transfer reaction (Badway et al., 2003): 


$$
\begin{gathered}
\mathrm{FeF}_{3}+\mathrm{Li}+\mathrm{e}^{-} \rightarrow \mathrm{LiFeF}_{3} \\
\mathrm{LiFeF}_{3}+2 \mathrm{Li}+2 \mathrm{e}^{-} \rightarrow \mathrm{Fe}^{0}+3 \mathrm{LiF}
\end{gathered}
$$

Guo synthesized the anhydrous $\mathrm{FeF}_{3}$ by a liquid-phase method combined with a thermal treatment process of the $\mathrm{FeF}_{3} \cdot 3 \mathrm{H}_{2} \mathrm{O}$ / MWCNTs composite (Guo et al., 2019b). During heat treatment, the $\mathrm{FeF}_{3} \cdot 3 \mathrm{H}_{2} \mathrm{O}$ crystal smooth surface became rough due to the release of crystal water and phase transformation, and more particles were broken into small nanoparticles. However, MWCNT fibers can still be evenly distributed among $\mathrm{FeF}_{3}$ particles by this simple and convenient method. The large bandgap of pristine $\mathrm{FeF}_{3}$ can hinder the transfer electrons, inducing more self-discharge reaction than electrode reaction. The electrochemical test showed that conductive MWCNTs can facilitate electron transfer, and the electrode reaction prioritized the self-discharge reaction. The additive MWCNTs led to a decrease of the total polarization of $\mathrm{FeF}_{3}$ from 45 to $10 \mathrm{~m} \Omega$, proving that the MWCNTs can form a conductive network among $\mathrm{FeF}_{3}$ particles and greatly improve the conductivity. Wang used a scalable and low-cost strategy to prepare a $\mathrm{CoF}_{2} / \mathrm{CNTs}$ cathode nanocomposite, and the capacity was achieved at $550 \mathrm{mAh} / \mathrm{g}$ with excellent mechanical properties (Wang et al., 2015). Other TMFs, such as $\mathrm{FeF}_{2}$ (Wang et al., 2011), $\mathrm{TiF}_{3}$ (Kitajou et al., 2017; Kitajou et al., 2019), and $\mathrm{MnF}_{3}$ (Read, 2012), have been successfully synthesized and exhibited excellent performance. The summary of the cathode type, size/thickness, phase, and performance of cathode materials in recent studies is shown in Supplementary Table S1.

\section{SUMMARY AND OUTLOOK}

Theoretic calculation is another tool for the design of highperformance cathode materials as shown in Figures 2A-D; many new materials have been designed to be potential candidates ( $\mathrm{Wu}$ and Yushin, 2017). The strength and weakness of metal sulfides, chlorides, and fluorides are summarized and compared as shown in Figure 2E. Currently, sulfides are most studied and widely used as cathode materials for thermal batteries, but they do not meet the new challenge with the development of military weapons and space exploration in the future. Chlorides and fluorides have relatively high voltage and decomposition temperature, which make them suitable for the high-energy-density and long-discharging-time battery. However, they are still at the infancy stage; more detailed studies need to be carried out for the real application.

For the future development of cathode materials for thermal batteries, they can be improved mainly from the following four aspects, as shown in Figure 2F:

1) High voltage $V_{\text {ocv }}$ : this is the most important factor that influences the power and energy density of the thermal battery. More importantly, a higher-voltage cell will use fewer series cells to achieve the demanding output voltage and a simpler battery management system. Thus, the higher effective mass ratio of active material is also helpful for further enhancement of energy density. In this respect, the metal fluoride has overall advantage over chloride, sulfide, or oxides, because of the higher electronegativity difference between fluorine and alkali metal.
2) High capacity $C_{c}$ : transition metal compound with multiple valency metal and nonmetal element will have multiple electron transfer reaction with a relative higher $\mathrm{n} / \mathrm{M}$ ratio, which leads to a higher capacity. Transition metals with high valency state compounds are potential materials

3) High decomposition temperature $T_{\text {decom: }}$ thermal battery discharging time depends on the lower and upper temperature limit of the working temperature window, $T_{\mathrm{dw}}$ and $\mathrm{T}_{\text {up }}$, which are usually determined by the melting point of electrolyte and the decomposition temperature of cathode, respectively. Usually, electrolyte is a mixture of halide salts with very high boiling temperature and decomposition temperature. So, the cathode decomposition temperature is usually $\mathrm{T}_{\text {up }}$. The larger the $\mathrm{T}_{\mathrm{up}}-\mathrm{T}_{\mathrm{dw}}$ difference, the longer the discharging time. Nanostructure materials often show lower $\mathrm{T}_{\text {decom }}$, but surface modification has shown increased $\mathrm{T}_{\text {decom. }}$. 4) High electron conductivity $\sigma_{\mathrm{e}}$ : the cathode that has higher electron conductivity will facilitate the ion/electron transfer and thus has low internal resistance and higher output voltage. More importantly, it can yield larger current and thus has a large output power. However, almost all these metal compounds are insulators; thus, proper surface or doping engineering is necessary to improve the conductivity.

Coating, doping, and tailoring the microstructure are effective methods to improve the discharge performance of cathode (Tan et al., 2016). Carbon modification is an effective method to improve the stability and conductivity of electrode materials (Oh et al., 2010; Chinnappan et al., 2016; Jiang et al., 2016; Li et al., 2016; Shan et al., 2016; Zhang et al., 2016; Liu et al., 2017c; Li et al., 2017). In real application, simultaneously improving these factors without hindering other factors is impossible. Optimizing the cell design or electrode designs, such as tape-casting and screening-printing, to increase the mass ratio of active material is another useful way to upgrade the energy density of batteries (Ko et al., 2017).

\section{AUTHOR CONTRIBUTIONS}

RL wrote the manuscript. YQ and WG were supervisors and proposed modifications to this work.

\section{FUNDING}

This work was supported by the National Natural Science Foundation of China (NSFC, Grant No. 51971037) and Open Research Fund of CNMGE Platform \& NSCC-TJ.

\section{SUPPLEMENTARY MATERIAL}

The Supplementary Material for this article can be found online at: https://www.frontiersin.org/articles/10.3389/fchem.2022.832972/ full\#supplementary-material 


\section{REFERENCES}

Au, M. (2003). Nanostructured thermal Batteries with High Power Density. J. Power Sourc. 115 (2), 360-366. doi:10.1016/S0378-7753(02)00627-4

Badway, F., Pereira, N., Cosandey, F., and Amatucci, G. G. (2003). Carbon-Metal Fluoride Nanocomposites: Structure and Electrochemistry of $\mathrm{FeF}_{3}: \mathrm{C}$. J. Electrochem. Soc. 150 (9), 1209-1218. doi:10.1149/1.1596162

Cha, Y. L., Park, I. H., Moon, K. H., Kim, D. H., Jung, S. I., and Yoon, Y. S. (2018). Simultaneous Control of Phase Transformation and Crystal of Amorphous $\mathrm{TiO}_{2}$ Coating on MWCNT Surface. J. Korean Ceram. Soc. 55 (6), 618-624. doi:10.4191/kcers.2018.55.6.09

Chang, Q., Luo, Z., Fu, L., Zhu, J., Yang, W., Li, D., et al. (2020). A New Cathode Material of $\mathrm{NiF}_{2}$ for thermal Batteries with High Specific Power. Electrochim. Acta 361, 137051. doi:10.1016/j.electacta.2020.137051

Chen, F., Jiang, C., Xu, L., Li, X., and Shen, Q. (2021). High Utilization Rate thermal Batteries Using $\mathrm{PbCl}_{2}$ as a Cathode Material. Mater. Lett. 299, 130018. doi:10. 1016/j.matlet.2021.130018

Chen, Y., Xu, S., Li, Y., Jacob, R. J., Kuang, Y., Liu, B., et al. (2017). $\mathrm{FeS}_{2}$ Nanoparticles Embedded in Reduced Graphene Oxide toward Robust, HighPerformance Electrocatalysts. Adv. Energ. Mater. 7 (19), 1700482. doi:10.1002/ aenm.201700482

Chinnappan, A., Baskar, C., Kim, H., and Ramakrishna, S. (2016). Carbon Nanotube Hybrid Nanostructures: Future Generation Conducting Materials. J. Mater. Chem. A, Mater. Energ. sustainability 4 (24), 9347-9361. doi:10.1039/ c6ta01717g

Cho, J.-H., Im, C. N., Choi, C. H., Ha, S.-h., Yoon, H.-K., Choi, Y., et al. (2020). Thermal Stability Characteristics of High-Power, Large-Capacity, reserve thermal Batteries with Pure $\mathrm{Li}$ and $\mathrm{Li}(\mathrm{Si})$ Anodes. Electrochimica Acta 353, 136612. doi:10.1016/j.electacta.2020.136612

Choi, Y.-S., Yu, H.-R., and Cheong, H.-W. (2015). Electrochemical Properties of a Lithium-Impregnated Metal Foam Anode for thermal Batteries. J. Power Sourc. 276, 102-104. doi:10.1016/j.jpowsour.2014.11.103

Choi, Y., Cho, S., and Lee, Y. (2014). Effect of the Addition of Carbon Black and Carbon Nanotube to $\mathrm{FeS}_{2}$ Cathode on the Electrochemical Performance of thermal Battery. J. Ind. Eng. Chem. 20 (5), 3584-3589. doi:10.1016/j.jiec.2013. 12.052

Chun, J., Jo, C., Sahgong, S., Kim, M. G., Lim, E., Kim, D. H., et al. (2016). Ammonium Fluoride Mediated Synthesis of Anhydrous Metal FluorideMesoporous Carbon Nanocomposites for High-Performance Lithium Ion Battery Cathodes. ACS Appl. Mater. Inter. 8 (51), 35180-35190. doi:10.1021/ acsami.6b10641

Ennaoui, A., Flechter, S., Smestad, G., and Tributsch, H. (1993). Iron Disulfide for Solar Energy Conversion. Sol. Energ. Mat. Sol. C. 29, 289-370. doi:10.1016/ 0927-0248(93)90095-K

Gao, J., Li, L., Tan, J., Sun, H., Li, B., Idrobo, J. C., et al. (2016). Vertically Oriented Arrays of $\mathrm{ReS}_{2}$ Nanosheets for Electrochemical Energy Storage and Electrocatalysis. Nano Lett. 16 (6), 3780-3787. doi:10.1021/acs.nanolett. $6 \mathrm{~b} 01180$

Giagloglou, K., Payne, J. L., Crouch, C., Gover, R. K. B., Connor, P., and Irvine, J. T. S. (2018). Transition Metal Chlorides $\mathrm{NiCl}_{2}, \mathrm{KNiCl}_{3}, \mathrm{Li}_{6} \mathrm{VCl}_{8}$ and $\mathrm{Li}_{2} \mathrm{MnCl}_{4}$ as Alternative Cathode Materials in Primary Li Thermal Batteries. J. Electrochem. Soc. 165 (14), 3510-3516. doi:10.1149/2.1231814jes

Giagloglou, K., Payne, J. L., Crouch, C., Gover, R. K. B., Connor, P. A., and Irvine, J. T. S. (2016). Zirconium Trisulfide as a Promising Cathode Material for Li Primary Thermal Batteries. J. Electrochem. Soc. 163 (14), A3126-A3130. doi:10. $1149 / 2.1351614$ jes

Gui, Y., Lin, X., Fu, L., Zhu, J., Yang, W., Li, D., et al. (2020). Shortening Activation Time of thermal Battery by Hydrogen Etching of $\mathrm{NiCl}_{2}$ Cathode. Mater. Lett. 275, 128136. doi:10.1016/j.matlet.2020.128136

Guidotti, R. A., and Masset, P. J. (2008). Thermally Activated ("thermal") Battery Technology. J. Power Sourc. 183, 388-398. doi:10.1016/j.jpowsour.2008.04.090

Guidotti, R. A., and Masset, P. (2006). Thermally Activated ("thermal") Battery Technology. J. Power Sourc. 161 (2), 1443-1449. doi:10.1016/j.jpowsour.2006. 06.013

Guidotti, R. A., Reinhardt, F. W., Dai, J., and Reisner, D. E. (2006). Performance of thermal Cells and Batteries Made with Plasma-Sprayed Cathodes and Anodes. J. Power Sourc. 160 (2), 1456-1464. doi:10.1016/j.jpowsour.2006.02.025
Guidotti, R. A., Reinhardt, F. W., Dai, J., Reisner, D. E., and Schwarz, R. (2002) Preparation and Characterization of Nanostructured FeS2 and CoS2 for HighTemperature Batteries. MRS Proc. 730. doi:10.1557/PROC-730-V7.3

Guo, S., Guo, H., Wang, X., Zhu, Y., Yang, M., Zhang, Q., et al. (2019). Synthesis and Electrochemical Performance of $\mathrm{WS}_{2}$ Nanosheet for thermal Batteries. Mater. Lett. 249, 81-83. doi:10.1016/j.matlet.2019.04.030

Guo, S. N., Guo, H., Wang, X., Zhu, Y., Hu, J., Yang, M., et al. (2019). Iron Trifluoride as a High Voltage Cathode Material for Thermal Batteries. J. Electrochem. Soc. 166 (15), A3599-A3605. doi:10.1149/2.0371915jes

Hu, J., Chu, Y., Tian, Q., Guo, S., Yang, M., Wang, X., et al. (2017). Electrochemical Properties of the $\mathrm{NiCl}_{2}$ Cathode with Nickel Foam Substrate for thermal Batteries. Mater. Lett. 207, 198-201. doi:10.1016/j.matlet.2017.07.082

Hu, J., Chu, Y., Tian, Q., Wang, J., Li, Y., Wu, Q., et al. (2018). Film Cathode for thermal Batteries Using a Screen-Printing Process. Mater. Lett. 215, 296-299. doi:10.1016/j.matlet.2017.12.114

Hua, X., Eggeman, A. S., Castillo-Martínez, E., Robert, R., Geddes, H. S., Lu, Z., et al. (2021). Revisiting Metal Fluorides as Lithium-Ion Battery Cathodes. Nat. Mater. 20 (6), 841-850. doi:10.1038/s41563-020-00893-1

Jai Prakash, L. R. D. R. (2000). Effect of Sodium Iodide Additive on the Electrochemical Performance of Sodium/nickel Chloride Cells. J. Appl. Electrochemistry 30, 1229-1233. doi:10.1023/A:1026539607417

Ji, Y., Liu, X., Liu, W., Wang, Y., Zhang, H., Yang, M., et al. (2014). A Facile Template-free Approach for the Solid-phase Synthesis of $\mathrm{CoS}_{2}$ Nanocrystals and Their Enhanced Storage Energy in Supercapacitors. RSC Adv. 4 (91), 50220-50225. doi:10.1039/C4RA08614G

Jiang, B., Han, C., Li, B., He, Y., and Lin, Z. (2016). In-Situ Crafting of $\mathrm{ZnFe}_{2} \mathrm{O}_{4}$ Nanoparticles Impregnated within Continuous Carbon Network as Advanced Anode Materials. ACS Nano 10 (2), 2728-2735. doi:10.1021/acsnano.5b07806

Jin, C., Fu, L., Zhu, J., Yang, W., Li, D., and Zhou, L. (2018). A Hierarchical Carbon Modified Nano-NiS 2 Cathode with High thermal Stability for a High Energy thermal Battery. J. Mater. Chem. A. 6 (16), 7123-7132. doi:10.1039/ C8TA00346G

Jin, C., Zhou, L., Fu, L., Zhu, J., and Li, D. (2017). Synthesis and Discharge Performances of $\mathrm{NiCl}_{2}$ by Surface Modification of Carbon Coating as Cathode Material of thermal Battery. Appl. Surf. Sci. 402, 308-313. doi:10.1016/j.apsusc. 2017.01.034

Jin, C., Zhou, L., Fu, L., Zhu, J., Li, D., and Yang, W. (2017). The Acceleration Intermediate Phase ( $\mathrm{NiS}$ and $\mathrm{Ni}_{3} \mathrm{~S}_{2}$ ) Evolution by Nanocrystallization in $\mathrm{Li}$ / $\mathrm{NiS}_{2}$ thermal Batteries with High Specific Capacity. J. Power Sourc. 352, 83-89. doi:10.1016/j.jpowsour.2017.03.119

Kim, I. Y., Woo, S. P., Ko, J., Kang, S., Yoon, Y. S., Cheong, H., et al. (2020). BinderFree Cathode for Thermal Batteries Fabricated Using FeS 2 Treated Metal Foam. Front. Chem. 7. doi:10.3389/fchem.2019.00904

Kim, S., Seo, D., Gwon, H., Kim, J., and Kang, K. (2010). Fabrication of $\mathrm{FeF}_{3}$ Nanoflowers on CNT Branches and Their Application to High Power Lithium Rechargeable Batteries. Adv. Mater. 22 (46), 5260-5264. doi:10.1002/adma. 201002879

Kitajou, A., Eguchi, K., Ishado, Y., Setoyama, H., Okajima, T., and Okada, S. (2019). Electrochemical Properties of Titanium Fluoride with High Rate Capability for Lithium-Ion Batteries. J. Power Sourc. 419, 1-5. doi:10.1016/j.jpowsour.2019. 02.056

Kitajou, A., Tanaka, I., Tanaka, Y., Kobayashi, E., Setoyama, H., Okajima, T., et al. (2017). Discharge and Charge Reaction of Perovskite-type $M_{3}(M=\mathrm{Fe}$ and Ti) Cathodes for Lithium-Ion Batteries. Electrochemistry 85 (8), 472-477. doi:10. 5796/electrochemistry.85.472

Ko, J., Kang, S. H., Cheong, H.-W., and Yoon, Y. S. (2019). Recent Progress in Cathode Materials for Thermal Batteries. J. Korean Ceram. Soc. 56 (3), 233-255. doi:10.4191/kcers.2019.56.3.05

Ko, J., Kim, I. Y., Jung, H. M., Cheong, H., and Yoon, Y. S. (2017). Thin Cathode for thermal Batteries Using a Tape-Casting Process. Ceram. Int. 43 (7), 5789-5793. doi:10.1016/j.ceramint.2017.01.126

Li, L., Meng, F., and Jin, S. (2012). High-capacity Lithium-Ion Battery Conversion Cathodes Based on Iron Fluoride Nanowires and Insights into the Conversion Mechanism. Nano Lett. 12 (11), 6030-6037. doi:10.1021/nl303630p

Li, X., Qian, K., He, Y., Liu, C., An, D., Li, Y., et al. (2017). A Dual-Functional GelPolymer Electrolyte for Lithium Ion Batteries with superior Rate and Safety Performances. J. Mater. Chem. A, Mater. Energ. sustainability 5 (35), 18888-18895. doi:10.1039/C7TA04415A 
Li, X., Sun, Y., Xu, X., Wang, Y., Chou, S., Cao, A., et al. (2019). Lotus Rhizome-like $\mathrm{S} / \mathrm{N}-\mathrm{C}$ with Embedded $\mathrm{WS}_{2}$ for superior Sodium Storage. J. Mater. Chem. A. 7 (45), 25932-25943. doi:10.1039/C9TA09373G

Li, Y., Hu, Y., Titirici, M., Chen, L., and Huang, X. (2016). Hard Carbon Microtubes Made from Renewable Cotton as High-Performance Anode Material for Sodium-Ion Batteries. Adv. Energ. Mater. 6 (18), 1600659. doi:10.1002/ aenm.201600659

Liang, J., Ma, S., Li, J., Wang, Y., Wu, J., Zhang, Q., et al. (2020). Boosting the Acidic Electrocatalytic Nitrogen Reduction Performance of $\mathrm{MoS}_{2}$ by Strain Engineering. J. Mater. Chem. A. 8 (20), 10426-10432. doi:10.1039/ D0TA03622F

Liu, W., Liu, H., Bi, S., Cao, L., and Sun, Y. (2017). Variable-temperature Preparation and Performance of $\mathrm{NiCl}_{2}$ as a Cathode Material for thermal Batteries. Sci. China Mater. 60 (3), 251-257. doi:10.1007/s40843-016-9003-x

Liu, X., Huang, J. Q., Zhang, Q., and Mai, L. (2017). Nanostructured Metal Oxides and Sulfides for Lithium-Sulfur Batteries. Adv. Mater. 29 (20). doi:10.1002/ adma.201601759

Liu, Z., Lu, T., Song, T., Yu, X., Lou, X. W. D., and Paik, U. (2017). Structuredesigned Synthesis of $\mathrm{FeS}_{2} @ \mathrm{C}$ Yolk-Shell Nanoboxes as a High-Performance Anode for Sodium-Ion Batteries. Energ. Environ. Sci. 10 (7), 1576-1580. doi:10. 1039/C7EE01100H

Masset, P. J., and Guidotti, R. A. (2008). Thermal Activated ("thermal") Battery Technology. J. Power Sourc. 177 (2), 595-609. doi:10.1016/j.jpowsour.2007. 11.017

Masset, P. J., and Guidotti, R. A. (2008). Thermal Activated ("thermal") Battery Technology. J. Power Sourc. 178 (1), 456-466. doi:10.1016/j.jpowsour.2007. 11.073

Masset, P., Schoeffert, S., Poinso, J., and Poignet, J. (2005). LiF-LiCl-LiI vs. LiF$\mathrm{LiBr}-\mathrm{KBr}$ as Molten Salt Electrolyte in Thermal Batteries. J. Electrochem. Soc. 152 (2), A405. doi:10.1149/1.1850861

Oh, S. W., Myung, S., Oh, S., Oh, K. H., Amine, K., Scrosati, B., et al. (2010). Double Carbon Coating of $\mathrm{LiFePO}_{4}$ as High Rate Electrode for Rechargeable Lithium Batteries. Adv. Mater. 22 (43), 4842-4845. doi:10.1002/adma.200904027

Park, J., Lee, S., Han, Y., Hwang, H., and Ryu, S. (2016). Effects of Debinding Atmosphere on Properties of Sintered Reaction-Bonded $\mathrm{Si}_{3} \mathrm{~N}_{4}$ Prepared by Tape Casting Method. J. Korean Ceram. Soc. 53 (6), 622-627. doi:10.4191/kcers. 2016.53.6.622

Payne, J. L., Percival, J. D., Giagloglou, K., Crouch, C. J., Carins, G. M., Smith, R. I., et al. (2017). In-Situ Thermal Battery Discharge Using $\mathrm{NiS}_{2}$ as a Cathode Material. ChemElectroChem 4 (8), 1916-1923. doi:10.1002/celc. 201700095

Payne, J. L., Percival, J. D., Giagloglou, K., Crouch, C. J., Carins, G. M., Smith, R. I., et al. (2019). In Situ Thermal Battery Discharge Using $\mathrm{CoS}_{2}$ as a Cathode Material. J. Electrochem. Soc. 166 (12), A2660-A2664. doi:10.1149/2.1431912jes

Preto, S. K., Tomczuk, Z., Von Winbush, S., and Roche, M. F. (1983). Reactions of $\mathrm{FeS}_{2}, \mathrm{CoS}_{2}$, and $\mathrm{NiS}_{2}$ Electrodes in Molten LiCl-KCl Electrolytes. J. Electrochem. Soc. 130 (2), 264-273. doi:10.1149/1.2119692

Read, W. K. B. A. (2012). A Study of Cobalt and Manganese Fluorides as Cathode Materials for Rechargeable Lithium Cells. Electrochem. Soc. 41 (41), 97-106. doi:10.1149/1.4717967

Sarma, P. V., Vineesh, T. V., Kumar, R., Sreepal, V., Prasannachandran, R., Singh, A. K., et al. (2020). Nanostructured Tungsten Oxysulfide as an Efficient Electrocatalyst for Hydrogen Evolution Reaction. ACS Catal. 10 (12), 6753-6762. doi:10.1021/acscatal.9b04177

Sen, U. K., and Mitra, S. (2013). High-Rate and High-Energy-Density Lithium-Ion Battery Anode Containing 2D MoS 2 Nanowall and Cellulose Binder. ACS Appl. Mater. Inter. 5 (4), 1240-1247. doi:10.1021/am3022015

Shan, J., Liu, Y., Su, Y., Liu, P., Zhuang, X., Wu, D., et al. (2016). Graphene-directed Two-Dimensional Porous Carbon Frameworks for High-Performance Lithium-Sulfur Battery Cathodes. J. Mater. Chem. A, Mater. Energ. sustainability 4 (1), 314-320. doi:10.1039/C5TA08109B

Sheng Nan Guo, H. G. X. W., and Wang, L. Z. A. J. (2019). Iron Trifluoride as a High Voltage Cathode Material for Thermal Batteries. J. Electrochem. Soc. 166 (15), 3599-3605. doi:10.1149/2.0371915jes

Tan, R., Yang, J., Hu, J., Wang, K., Zhao, Y., and Pan, F. (2016). Core-shell Nano$\mathrm{FeS}_{2} @ \mathrm{~N}$-Doped Graphene as an Advanced Cathode Material for Rechargeable Li-Ion Batteries. Chem. Commun. (Camb) 52 (5), 986-989. doi:10.1039/ c5 $c 008002 \mathrm{a}$
Thu, T. T., Thu, T. T., Manh, T. D., Tan, T., and Chang, J. (2021). An Assessment of Pyrite Thin-Film Cathode Characteristics for thermal Batteries by the Doctor Blade Coating Method. J. Mater. Res. Tech. 13, 1139-1149. doi:10.1016/j.jmrt. 2021.05.014

Tian, Q., Wang, J., Xiang, W., Zhao, J., Guo, H., Hu, J., et al. (2021). Fabrication of the $\mathrm{Ni}-\mathrm{NiCl}_{2}$ Composite Cathode Material for Fast-Response Thermal Batteries. Front. Chem. 9, 679231. doi:10.3389/fchem.2021.679231

Tomczuk, Z., Tani, B., Otto, N. C., Roche, M. F., and Vissers, D. R. (1982). Phase Relationships in Positive Electrodes of High Temperature Li - Al/LiCl - KCl/ $\mathrm{FeS}_{2}$ Cells. J. Electrochem. Soc. 129 (5), 925-931. doi:10.1149/1.2124067

Wang, F., Robert, R., Chernova, N. A., Pereira, N., Omenya, F., Badway, F., et al. (2011). Conversion Reaction Mechanisms in Lithium Ion Batteries: Study of the Binary Metal Fluoride Electrodes. J. Am. Chem. Soc. 133 (46), 18828-18836. doi:10.1021/ja206268a

Wang, X., Gu, W., Lee, J. T., Nitta, N., Benson, J., Magasinski, A., et al. (2015). Carbon Nanotube- $\mathrm{CoF}_{2}$ Multifunctional Cathode for Lithium Ion Batteries: Effect of Electrolyte on Cycle Stability. Small 11 (38), 5164-5173. doi:10.1002/ smll.201501139

Wang, X., Li, R., Yang, H., Zheng, J., Li, Y., Zhu, P., et al. (2021). Epitaxial Growth of Atomically Thick WSe $\mathrm{W}_{2}$ Nanoribbons. Vacuum 189, 110254. doi:10.1016/j. vacuum.2021.110254

Wang, X., Wang, G., Chen, J., Zhu, X., Tian, J., Jiang, C., et al. (2013). Pyrite Thin Films Prepared for thermal Batteries via Sulfuring Electrodeposited Iron Sulfide Films: Structure and Physical Properties. Mater. Lett. 110, 144-147. doi:10. 1016/j.matlet.2013.07.107

Wu, F., and Yushin, G. (2017). Conversion Cathodes for Rechargeable Lithium and Lithium-Ion Batteries. Energ. Environ. Sci. 10 (2), 435-459. doi:10.1039/C6EE02326F

Xie, S., Deng, Y., Mei, J., Yang, Z., Lau, W., and Liu, H. (2017). Carbon Coated $\mathrm{CoS}_{2}$ thermal Battery Electrode Material with Enhanced Discharge Performances and Air Stability. Electrochim. Acta 231, 287-293. doi:10.1016/j.electacta.2017.02.068

Xie, S., Deng, Y., Mei, J., Yang, Z., Lau, W., and Liu, H. (2016). Facile Synthesis of $\mathrm{CoS}_{2} / \mathrm{CNTs}$ Composite and its Exploitation in thermal Battery Fabrication. Composites B: Eng. 93, 203-209. doi:10.1016/j.compositesb.2016.03.038

Xie, Y., Liu, Z., Ning, H., Huang, H., and Chen, L. (2018). Suppressing SelfDischarge of $\mathrm{Li}-\mathrm{B} / \mathrm{CoS}_{2}$ thermal Batteries by Using a Carbon-Coated $\mathrm{CoS}_{2}$ Cathode. RSC Adv. 8 (13), 7173-7178. doi:10.1039/C7RA13071F

Xu, X., Liu, W., Kim, Y., and Cho, J. (2014). Nanostructured Transition Metal Sulfides for Lithium Ion Batteries: Progress and Challenges. Nano Today 9 (5), 604-630. doi:10.1016/j.nantod.2014.09.005

Xu, X., Tian, X., Sun, B., Liang, Z., Cui, H., Tian, J., et al. (2020). 1 T-phase Molybdenum Sulfide Nanodots Enable Efficient Electrocatalytic Nitrogen Fixation under Ambient Conditions. Appl. Catal. B: Environ. 272, 118984. doi:10.1016/j.apcatb.2020.118984

Yamakawa, N., Jiang, M., and Grey, C. P. (2009). Investigation of the Conversion Reaction Mechanisms for Binary Copper(II) Compounds by Solid-State NMR Spectroscopy and X-ray Diffraction. Chem. Mater. 21 (14), 3162-3176. doi:10. $1021 / \mathrm{cm} 900581 \mathrm{~b}$

Yang, Z., Liu, X., Feng, X., Cui, Y., and Yang, X. (2014). Hydrothermal Synthesized Micro/nano-Sized Pyrite Used as Cathode Material to Improve the Electrochemical Performance of thermal Battery. J. Appl. Electrochem. 44 (10), 1075-1080. doi:10.1007/s10800-014-0724-9

Ying, C., Yun-Wei, L., Qi-Bing, W., Jing, H., Qian-Qiu, T., and He-Long, H. (2016). In-situ Synthesis and Discharge Performance of Ni-NiCl\$lt;inf\$gt;2\$1t;inf\$gt; Composite as Cathode Materials for Thermal Batteries. J. Inorg. Mater. 31 (9), 992-996. doi:10.15541/jim20160085

Yu, L., Hu, H., Wu, H. B., and Lou, X. W. (2017). Complex Hollow Nanostructures: Synthesis and Energy-Related Applications. Adv. Mater. 29 (15). doi:10.1002/ adma.201604563

Yu, X., Yu, L., and Lou, X. W. D. (2016). Metal Sulfide Hollow Nanostructures for Electrochemical Energy Storage. Adv. Energ. Mater. 6 (3), 1501333. doi:10. 1002/aenm.201501333

Yusong Choi, T. A. S. H. (2019). Hydrothermally Synthesized Homogeneous $\mathrm{Ni}$-Mo-S Structures on Ni-Foam Cathodes for thermal Batteries. Chem. Commun. 55, 7300. doi:10.1039/c9cc03388b

Zeng, L., Li, X., Chen, S., Wen, J., Huang, W., and Chen, A. (2020). Unique Hollow $\mathrm{Ni}-\mathrm{Fe} @ \mathrm{MoS}_{2}$ Nanocubes with Boosted Electrocatalytic Activity for $\mathrm{N}_{2}$ Reduction to $\mathrm{NH}_{3}$. J. Mater. Chem. A. 8 (15), 7339-7349. doi:10.1039/ C9TA13336D 
Zhang, S. S., and Tran, D. T. (2018). Pyrite $\mathrm{FeS}_{2}$ as an In-Situ Oxygen Remover for Rechargeable Batteries with Layered Cathode Materials. J. Power Sourc. 403, 167-172. doi:10.1016/j.jpowsour.2018.09.079

Zhang, X., Lai, Z., Ma, Q., and Zhang, H. (2018). Novel Structured Transition Metal Dichalcogenide Nanosheets. Chem. Soc. Rev. 47 (9), 331-3338. doi:10.1039/ c8cs00094h

Zhang, X., Zhang, X., Wang, X., Xie, Z., and Zhou, Z. (2016). $\mathrm{NiFe}_{2} \mathrm{O}_{4}-\mathrm{CNT}$ Composite: an Efficient Electrocatalyst for Oxygen Evolution Reactions in Li-O $\mathrm{O}_{2}$ Batteries Guided by Computations. J. Mater. Chem. A. 4 (24), 9390-9393. doi:10.1039/C6TA02779B

Zheng, X., Zhu, Y., Sun, Y., and Jiao, Q. (2018). Hydrothermal Synthesis of $\mathrm{MoS}_{2}$ with Different Morphology and its Performance in thermal Battery. J. Power Sourc. 395, 318-327. doi:10.1016/j.jpowsour.2018.05.092

Zou, J., Zhao, J., Wang, B., Chen, S., Chen, P., Ran, Q., et al. (2020). Unraveling the Reaction Mechanism of $\mathrm{FeS}_{2}$ as a Li-Ion Battery Cathode. ACS Appl. Mater. Inter. 12 (40), 44850-44857. doi:10.1021/acsami.0c14082
Conflict of Interest: The authors declare that the research was conducted in the absence of any commercial or financial relationships that could be construed as a potential conflict of interest.

Publisher's Note: All claims expressed in this article are solely those of the authors and do not necessarily represent those of their affiliated organizations, or those of the publisher, the editors, and the reviewers. Any product that may be evaluated in this article, or claim that may be made by its manufacturer, is not guaranteed or endorsed by the publisher.

Copyright (c) $2022 \mathrm{Li}$, Guo and Qian. This is an open-access article distributed under the terms of the Creative Commons Attribution License (CC BY). The use, distribution or reproduction in other forums is permitted, provided the original author(s) and the copyright owner(s) are credited and that the original publication in this journal is cited, in accordance with accepted academic practice. No use, distribution or reproduction is permitted which does not comply with these terms. 